\title{
THE INFLUENCE OF MOLYBDENUM AND TUNGSTEN ON THE CRM-OXIDE CATALYST REACTIVITY IN PROPANE ACTIVATION: A QUANTUM MECHANICS CALCULATION
}

\author{
Toyese OYEGOKE ${ }^{*}$, Fadimatu N. DABAI ${ }^{1}$, Adamu UZAIRU ${ }^{2}$, Baba El-Yakubu JIBRIL ${ }^{1}$ \\ ${ }^{1}$ Chemical Engineering Department, Faculty of Engineering, Ahmadu Bello University Zaria, Nigeria. \\ ${ }^{2}$ Chemistry Department, Faculty of Physical Sciences, Ahmadu Bello University Zaria, Nigeria.
}

\begin{abstract}
A quantum chemical calculation for the activation of propane across $C r M$-oxide $(M=C r, M o$, and $W$ ) catalysts in the dehydrogenation of propane into propylene was studied. The calculation was carried out via the use of the PM3 semi-empirical approach. In this study, the reactivity of the catalyst was examined through the use of reactivity parameters such as $C-H$ bond abstraction activation energy (Ea), energy bandgap (Egap), and its adsorption energy (Eads) during the dehydrogenation of propane. This study further identifies the effects of introducing promoters such as molybdenum (Mo) and tungsten (W) on chromium (III) oxide catalysts were evaluated. The findings show that $W$ increases the catalyst's binding energy for the isopropyl species, while Mo slightly reduces it. The structures' energy band gaps indicate that $W$ reduces stability, while the presence of Mo increases stability. The study of the propane activation mechanism across the surface of CrM-oxides $(M=C r, M o$, and $W)$ identifies $O$-Cr pair sites were found to be a thermodynamically feasible route for the activation of $\mathrm{H}$-Cl with a lesser energy demand on the unmodified-surface. The modification of the surface using tungsten $(W)$ was found to have speed up the rate of propane activation on the $\mathrm{H}-\mathrm{C} 1$ bond across $\mathrm{W}-\mathrm{O}$ pair sites. This finding was due to the lower activation energy shown for the route. However, this study confirms that tungsten's introduction promotes propane activation, while molybdenum slightly reduces the activation rate. Thus, tungsten would be more promising for promoting propane activation rate, while molybdenum is a potential promoter for enhancing propane dehydrogenation's catalyst stability.
\end{abstract}

Keywords: Propane activation, Dehydrogenation, Semi-empirical calculation, Chromium oxide, Lewis acidity, Adsorption energy.

\section{Introduction}

The significance of reactive and valuable materials like ethylene, propylene, and many others cannot be overemphasized. These alkenes are usually known to be vital precursors in the petrochemical production in our industries. Propylene has been rated as one of the most important precursors in process industries due to its wide range of applications; some of these applications include using it as a feedstock to produce relevant materials like polypropylene, isopropanol, epichlorohydrin, propylene oxide, and acrylonitrile [1,2]. The propane's direct conversion into propylene has suffered many challenges, which are majorly attributed to the catalyst's performance [3, 4]. Most of the existing industries have been using platinum and chromium oxide. These catalysts have been reportedly found to have suffered from rapid deactivation coupled with poor selectivity [5, 6], which results in low yield [5, 6]. Previous works such as Gascón et al. [7, 6] attest that the $\mathrm{Cr}_{2} \mathrm{O}_{3}$ catalyst in its pure form shows poor catalyst selectivity for desired products and rapidly deactivates. In the 2020 market report for the global polypropylene, it was reported that the polypropylene market worth $\$ 126.03$ billion in 2019 and had been projected to rise to 
$\$ 192.33$ billion by 2023 at a compound annual growth rate of $12 \%$, which was associated with the rising demand of thermoplastic materials [8]. The thermoplastic materials have been proven to be of good chemical properties and recyclable without altering their physical properties, making them useful in clothing, packaging, and many other applications.

Researchers are investigating the best approach to combat these challenges encountered in propylene production to meet the rising demand for propylene better. The earlier research has majorly focused on using the experimental approach; only a few considered using a theoretical approach to address this challenge. Some of the works that considered the use of theoretical approach includes Yan et al. [9] that used Density Functional Theory (DFT) calculation to propose a reaction mechanism for propane dehydrogenation for the use of $\mathrm{Ga}_{2} \mathrm{O}_{3}$ (100), where $\mathrm{H}$ abstraction by $\mathrm{O}(2)$ site was found to be of the low energy barrier. Another work is Ming et al. [10] studies that use DFT calculations to show that alloying platinum catalyst with tin decreases the energy barrier for propylene desorption and simultaneously increases the activation energy of propylene dehydrogenation, which has a significant effect on the catalyst selectivity of propylene production. Lauri and Karoliina [11] also made related deductions for the use of Sn to alloy Pt catalyst, unveiling that it would result in a lower coking rate and thereby weaken the propylene affinity for the surface. Timothy [12] confirmed that PtGa alloy has superior catalytic properties than Sn-Ga alloy and similar properties to those deduced for Pt-Sn alloy, as reported by Lauri and Karoliina [11]. Stephanie et al. [13] found that an increase in hydrogen pressure lowers the coverage of deeply dehydrogenated coke precursors on the surface. Other similar findings have been reported in the literature $[5,6,14-16]$. Looking at the fact the most studies have been focusing on the improvement of Pt catalyst, in recent times, Oyegoke et al. [17] considered the study of chromium oxide catalyst. The study indicated that the chromium sites are highly acidic and reactive compared to the oxygen sites, identifying the chromium site as the main active site in promoting propane dehydrogenation into propylene over $\mathrm{Cr}_{2} \mathrm{O}_{3}$ catalyst. In recent studies [18], the introduction of tungsten on the $\mathrm{Cr}_{2} \mathrm{O}_{3}$ catalyst was more promising than molybdenum due to the better avenue it offers to promote electron exchange and higher acidity.

The search has shown that no work has evaluated the role of foreign material like molybdenum (Mo) and tungsten (W) in affecting the performance of the $\mathrm{Cr}_{2} \mathrm{O}_{3}$ catalyst. Therefore, in this current study, an approximation of the parameterized method 3 (PM3) of the semi-empirical theory was used to evaluate isopropyl and propylene's adsorption energies. The influence of the catalyst sites' acidity (Lewis) on propane activation was investigated in the presence of Mo and W (including a case where there is no foreign material). The understanding provided would give insight into the best way to improving the performance of a chromium oxide catalyst in the production of propylene. Moreover, the role played by the Lewis acidity of the catalyst is better understood.

\section{Computational Methodology}

In this study, the computations were carried out with the use of the Semi-empirical Parameterized Model 3 (PM3) calculation method in the SPARTAN 18 software package and ran on an HP 15 Pavilion Notebook (Intel Core i3 Processor @ 1.8 GHz and 6 GB RAM). This study employed the use of Spartan 14 to carry out all the molecular simulations, while Microsoft Excel was used to aid both the mathematical and statistical analysis carried out. ACD/ChemSketch 11 was employed in sketching the structure of the molecules.

\section{Choice of cluster structures}

The molecular structures employed in representing chromium (III) oxide catalyst clusters or slabs were adopted for Compere et al. [19], which was found to be in line with the clusters employed in literature studies [9, 17-21] while that of the probes and reactant was built to be in line with the molecular structure present in PubChem online database. Also, the modified surface 
of the catalyst (or modified form of the catalyst cluster) was built through the substitution of one chromium site on the chromium (III) oxide cluster with different metals such as molybdenum (Mo) and tungsten (W); otherwise known as a promoter to yield two new structures named to be 'Mo-modified catalyst surface or cluster' and 'W-modified catalyst surface or cluster.' Fig. 1 pictorially displays the molecular structures employed in this study.

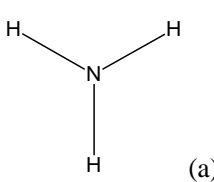

(e)

(a)
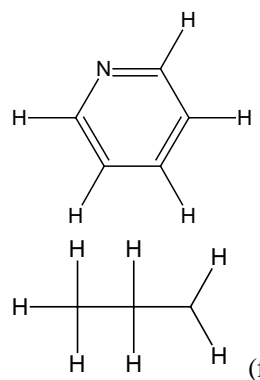

(b)

(f)

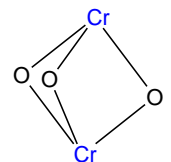

(c)

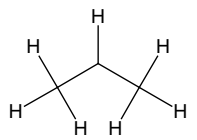

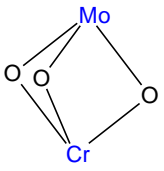

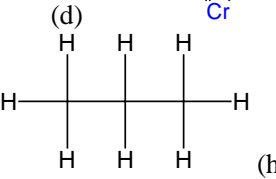

Fig. 1. Molecular structure of molecular probes (a-b), unmodified catalyst cluster (c), modified catalyst cluster (d-e), Isopropyl species (f-g), propane (h)

\section{Ground-state geometrical optimizations}

The structures of the catalyst, reactant, and molecular probe structures were built and minimized using the molecular mechanics (MMFF) method to remove strain energy. After this, geometry optimizations and energy computations were subsequently calculated on the energy minimized structures using the PM3 basis set of a semi-empirical method at the ground state. Infrared (IR) frequency, orbital, and energies calculations were carried out on all optimized structures, and the absence of any imaginary frequencies confirmed that each optimized structure was located at a minimum on its IR spectra plot. All computations are made with an SCF tolerance of $10^{-9}$. The PM3 basis set was employed because literature confirms it is one of the best for computations that involve transition metals, such as chromium [20, 21].

\section{Transition-state geometrical optimization}

At first, a guess transition-state structure was first built, after which the transition state optimization calculations were only performed using the guess structure alongside IR and energy calculations. PM3 was equally employed in this transition state search. All computations are made with an SCF tolerance of $10^{-9}$. Following the transition, state frequency calculations were performed to verify the TS nature of the structure, i.e., confirming that the structure had one, and one only, imaginary vibration frequency. Frequency calculations were also performed on the ground-state structures of the reference compounds. Fig. 2 shows that the different transition states geometry search carried out across different sites in this study. The activation energies (Ea) were obtained through the subtraction of transition state energy (Et) from the total energy of the reacting molecules $(\mathrm{Er})$, that is, $\mathrm{Ea}=\mathrm{Er}-\mathrm{Et}$, which was in accordance with the literature [20].

\section{Adsorption energy and other computations}

The heat of formation for the adsorbed species, catalyst slab, and catalyst slab with adsorbed species was calculated. The Infra-Red spectra, molecular, thermodynamics, and physiochemical parameters were evaluated from the computational approach employed. Adsorption energies were calculated using Equation (1), which was in line with the literature [15, 19, 20-22]:

$$
\mathrm{E}_{\mathrm{ads}}=\mathrm{E}_{\mathrm{pq}}-\mathrm{E}_{\mathrm{p}}-\mathrm{E}_{\mathrm{q}}
$$


Where,

$\mathrm{E}_{\text {ads }}=$ adsorption energy

$\mathrm{E}_{\mathrm{p}}=$ total energy of adsorbate $(\mathrm{p})$

$E_{q}=$ total energy of free cluster or catalyst slab (q)

$\mathrm{E}_{\mathrm{pq}}=$ total energy of adsorbed cluster or catalyst slab with adsorbate (pq)
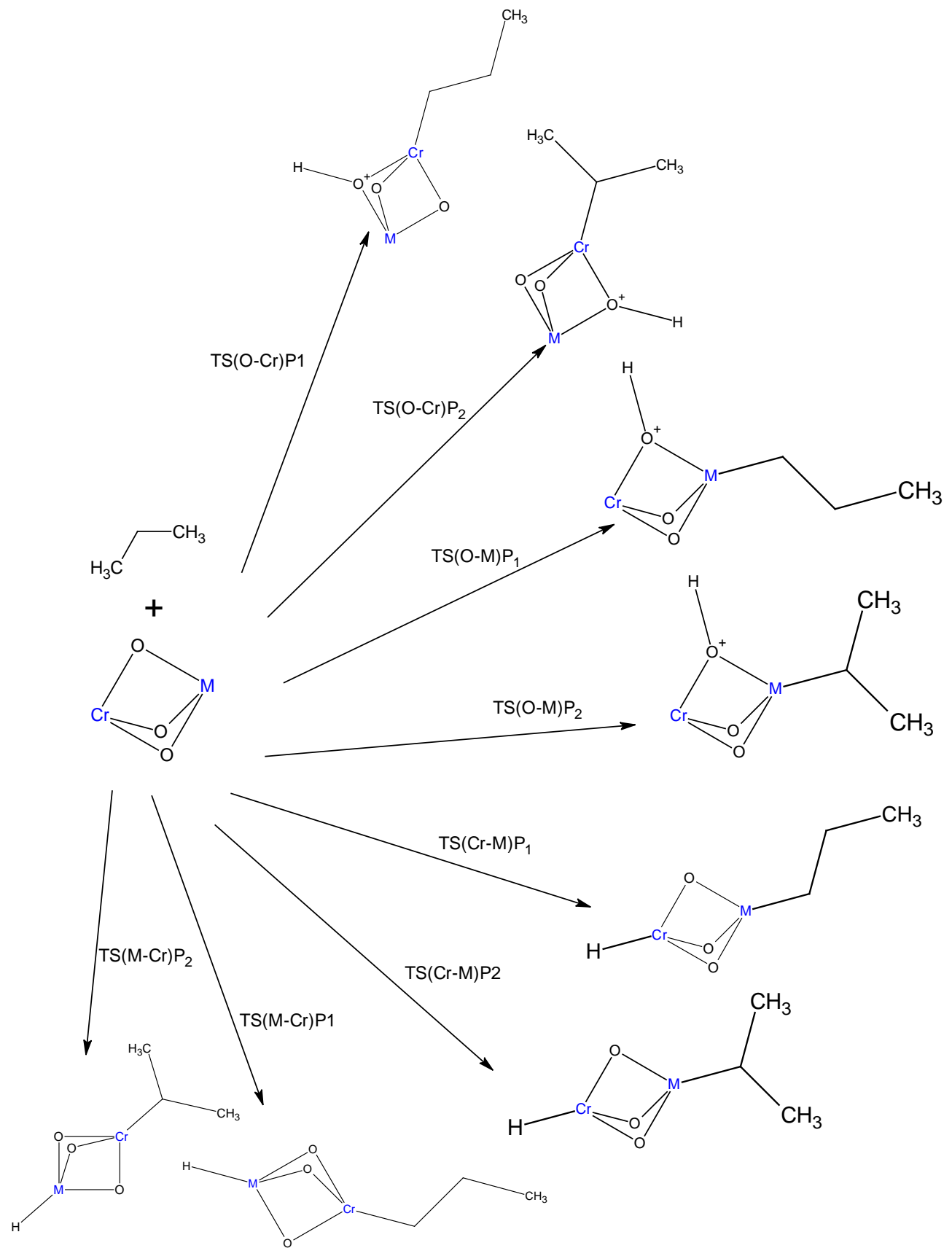

Fig 2. a). Different Propane Activation Route over CrM-oxide ( $\mathrm{M}=\mathrm{Cr}$, Mo, and W) Catalysts 


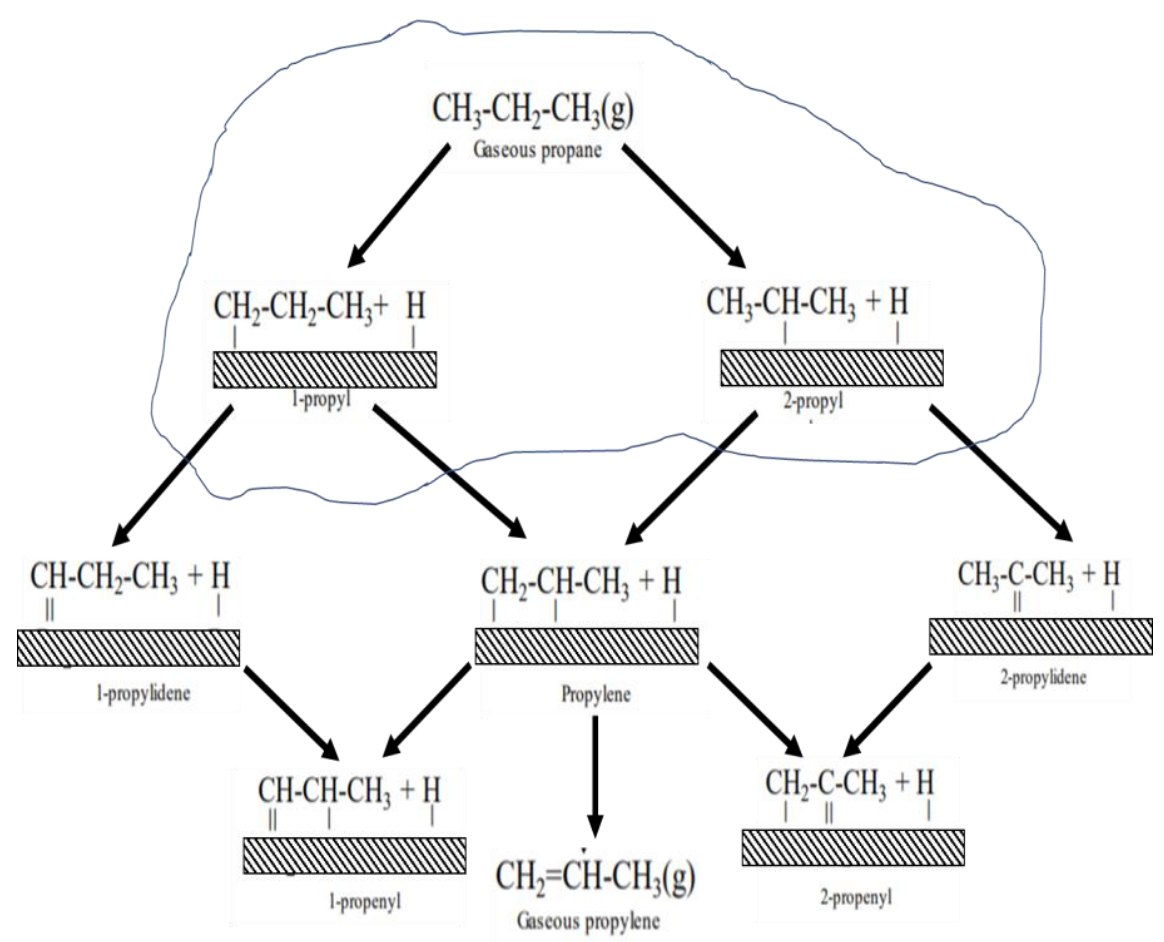

Fig 2. b). Different Propane Activation Route over CrM-oxide ( $\mathrm{M}=\mathrm{Cr}$, $\mathrm{Mo}$, and $\mathrm{W})$ Catalyst in Propane Dehydrogenation Mechanisms

\section{Lewis acidity collection}

The Lewis acidity of the catalyst sites was obtained from previous studies [18] on the same structures, which were evaluated via the use of pyridine and ammonia (presented in Table 1) as a molecular probe for the Lewis acidity calculation using their adsorption energies in line with the method employed in the literature $[22,23,17]$ in the measurement of Lewis acidity.

Table 1. Molecular Properties of the Catalysts (Oyegoke et al., 2020).

\begin{tabular}{|c|c|c|c|c|c|c|c|c|c|c|c|}
\hline Name & Formula & 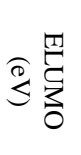 & $\stackrel{\substack{\pi \\
\hdashline}}{\stackrel{\pi}{0}}$ & $\stackrel{\pi}{\stackrel{2}{S}}$ & 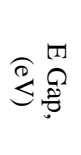 & 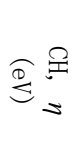 & 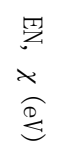 & $\begin{array}{l}0 \\
= \\
\stackrel{0}{0}\end{array}$ & 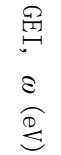 & $\begin{array}{l}\text { aAc } \\
\text { (avg) }\end{array}$ & pAc (avg) \\
\hline Chromia & $\mathrm{Cr}_{2} \mathrm{O}_{3}$ & -2.68 & -14.51 & -0.88 & 11.83 & 5.92 & 8.60 & -8.60 & 3.12 & -5.08 & -5.59 \\
\hline Mo-Chromia & $\mathrm{CrMoO}_{3}$ & -1.31 & -14.89 & -0.73 & 13.58 & 6.79 & 8.10 & -8.10 & 2.42 & -4.39 & -4.94 \\
\hline W-Chromia & $\mathrm{CrWO}_{3}$ & 0.37 & -12.80 & -2.26 & 13.17 & 6.59 & 6.22 & -6.22 & 1.47 & -8.99 & -10.05 \\
\hline Propane & $\mathrm{C}_{3} \mathrm{H}_{8}$ & 3.71 & -11.51 & -1.02 & 15.22 & 7.61 & 3.90 & -3.90 & 0.50 & - & - \\
\hline
\end{tabular}

\section{Acidity-reactivity correlation analysis}

The effects of Lewis acidity on the adsorption strength of the propane activation species (propyl-1 and propyl-2) across the catalyst cluster sites were investigated to identify the metal that exhibits a promising material for improving $\mathrm{Cr}_{2} \mathrm{O}_{3}$ catalytic performance by showing a stronger affinity and binding force for the isopropyl adsorption. The relationship between catalyst Lewis acidity (Ac), propane activation energy, or first hydrogen abstraction's activation energy (Ea) and the activation species adsorption strength (Eads) using statistical analysis, which was done with the aid of Microsoft Excel 2013 software. 


\section{Results and Discussions}

\section{Study of Propane Activation Mechanism over CrM-Oxide Surfaces}

The propane activation evaluation outcome in terms of potential activation mechanism regarding their energy barriers across different catalyst surfaces presented in Table 2, showing the mechanism on $\mathrm{CrM}$ - oxides $(\mathrm{M}=\mathrm{Cr}$, Mo, and $\mathrm{W})$ surfaces.

Table 2. Total Energy Data for $\mathrm{Cr}_{2} \mathrm{O}_{3}, \mathrm{CrMoO}_{3}$, and $\mathrm{CrWO}_{3}$ for Propane Activation (R, X, RX, TS, and UX represent is reactant, catalyst, adsorbed $\mathrm{R}$, transition state, and intermediate)

\begin{tabular}{|c|c|c|c|c|c|c|c|c|c|c|c|c|c|c|c|c|c|}
\hline $\begin{array}{c}\mathrm{Cr}_{2} \mathrm{O}_{3} \\
\text { Site }\end{array}$ & $\begin{array}{l}\mathrm{R}+\mathrm{X} \\
(\mathrm{eV})\end{array}$ & $\begin{array}{l}\mathrm{RX} \\
(\mathrm{eV})\end{array}$ & $\begin{array}{c}\mathrm{TS} \\
(\mathrm{eV})\end{array}$ & $\begin{array}{c}\text { UX } \\
(\mathrm{eV})\end{array}$ & $\begin{array}{c}\mathrm{Ea} \\
(\mathrm{eV})\end{array}$ & $\begin{array}{c}\mathrm{CrMoO}_{3} \\
\text { Site } \\
\end{array}$ & $\begin{array}{l}\mathrm{R}+\mathrm{X} \\
(\mathrm{eV})\end{array}$ & $\begin{array}{c}\mathrm{RX} \\
(\mathrm{eV})\end{array}$ & $\begin{array}{c}\mathrm{TS} \\
(\mathrm{eV})\end{array}$ & $\begin{array}{l}\mathrm{UX} \\
(\mathrm{eV})\end{array}$ & $\begin{array}{c}\mathrm{Ea} \\
(\mathrm{eV})\end{array}$ & $\begin{array}{c}\mathrm{CrWO}_{3} \\
\text { Site }\end{array}$ & $\begin{array}{r}\mathrm{R}+\mathrm{X} \\
(\mathrm{eV})\end{array}$ & $\begin{array}{l}\mathrm{RX} \\
(\mathrm{eV})\end{array}$ & $\begin{array}{c}\text { TS } \\
(\mathrm{eV})\end{array}$ & $\begin{array}{l}\mathrm{UX} \\
(\mathrm{eV})\end{array}$ & $\begin{array}{c}\mathrm{Ea} \\
(\mathrm{eV})\end{array}$ \\
\hline $\begin{array}{l}\mathrm{H}-\mathrm{P} 1 \\
(\mathrm{O}-\mathrm{Cr})\end{array}$ & -1.9 & -2.95 & -1.49 & -4.77 & 1.46 & $\begin{array}{l}\mathrm{H}-\mathrm{P} 1 \\
(\mathrm{O}-\mathrm{Cr})\end{array}$ & -1.75 & -1.75 & 0.78 & -2.41 & 2.53 & $\begin{array}{l}\text { H-P1 } \\
(\mathrm{O}-\mathrm{Cr})\end{array}$ & -3.28 & -8.15 & -5.2 & -9.5 & 2.95 \\
\hline $\begin{array}{l}\mathrm{H}-\mathrm{P} 2 \\
(\mathrm{O}-\mathrm{Cr})\end{array}$ & -1.9 & -2.78 & 3.07 & -4.54 & 5.85 & $\begin{array}{l}\mathrm{H}-\mathrm{P} 2 \\
(\mathrm{O}-\mathrm{Cr})\end{array}$ & -1.75 & -1.75 & 1.39 & -2.27 & 3.14 & $\begin{array}{l}\mathrm{H}-\mathrm{P} 2 \\
(\mathrm{O}-\mathrm{Cr})\end{array}$ & -3.28 & -7.83 & -4.27 & -7.13 & 3.56 \\
\hline $\begin{array}{l}\text { H-P1 } \\
\text { (Cr-O) }\end{array}$ & -1.9 & -2.95 & 2.49 & -3.34 & 5.44 & $\begin{array}{l}\text { H-P1 } \\
(\mathrm{O}-\mathrm{M})\end{array}$ & -1.75 & -3.82 & 2.05 & -1.39 & 5.87 & $\begin{array}{l}\text { H-P1 } \\
(\mathrm{O}-\mathrm{M})\end{array}$ & -3.28 & -6.26 & -3.28 & -8.57 & 2.98 \\
\hline $\begin{array}{l}\mathrm{H}-\mathrm{P} 2 \\
(\mathrm{Cr}-\mathrm{O})\end{array}$ & -1.9 & -2.78 & 2.79 & -3.3 & 5.57 & $\begin{array}{l}\text { H-P2 } \\
(\mathrm{O}-\mathrm{M})\end{array}$ & -1.75 & -3.93 & 4.93 & -1.84 & 8.86 & $\begin{array}{l}\text { H-P2 } \\
(\mathrm{O}-\mathrm{M})\end{array}$ & -3.28 & -8.26 & -6.31 & -6.91 & 1.95 \\
\hline $\begin{array}{l}\text { H-P1 } \\
(\mathrm{Cr}-\mathrm{Cr})\end{array}$ & -1.9 & -2.95 & 1.02 & -4.66 & 3.97 & $\begin{array}{l}\text { H-P1 } \\
\text { (Cr-O) }\end{array}$ & -1.75 & -1.75 & 5.02 & -4.34 & 6.77 & $\begin{array}{l}\text { H-P1 } \\
(\mathrm{Cr}-\mathrm{O})\end{array}$ & -3.28 & -8.15 & -5.33 & -9.22 & 2.82 \\
\hline $\begin{array}{l}\mathrm{H}-\mathrm{P} 2 \\
(\mathrm{Cr}-\mathrm{Cr})\end{array}$ & -1.9 & -2.78 & 1.31 & -4.93 & 4.09 & $\begin{array}{l}\mathrm{H}-\mathrm{P} 2 \\
(\mathrm{Cr}-\mathrm{O})\end{array}$ & -1.75 & -1.75 & 8.75 & -4.1 & 10.5 & $\begin{array}{l}\mathrm{H}-\mathrm{P} 2 \\
(\mathrm{Cr}-\mathrm{O})\end{array}$ & -3.28 & -7.83 & -4.88 & -9.3 & 2.95 \\
\hline $\begin{array}{l}\text { H-P1 (O- } \\
\text { O) }\end{array}$ & -1.9 & -2.95 & 5.78 & -1.86 & 8.73 & $\begin{array}{l}\text { H-P1 } \\
\text { (M-O) }\end{array}$ & -1.75 & -3.82 & 1.58 & -4.67 & 5.4 & $\begin{array}{l}\text { H-P1 } \\
\text { (M-O) }\end{array}$ & -3.28 & -6.26 & -5.08 & -7.77 & 1.18 \\
\hline \multirow[t]{7}{*}{$\begin{array}{c}\text { H-P2 (O- } \\
\text { O) }\end{array}$} & -1.9 & -2.78 & 2.23 & -1.65 & 5.01 & $\begin{array}{l}\text { H-P2 } \\
(\mathrm{M}-\mathrm{O})\end{array}$ & -1.75 & -3.93 & 6.17 & -4.27 & 10.1 & $\begin{array}{l}\text { H-P2 } \\
(\mathrm{M}-\mathrm{O})\end{array}$ & -3.28 & -8.26 & -2.48 & -7.7 & 5.78 \\
\hline & & & & & & $\begin{array}{l}\text { H-P1 } \\
(\mathrm{Cr}-\mathrm{M})\end{array}$ & -1.75 & -1.75 & 16.25 & -2.51 & 18 & $\begin{array}{l}\text { H-P1 } \\
\text { (Cr-M) }\end{array}$ & -3.28 & -8.15 & -4.27 & -6.98 & 3.88 \\
\hline & & & & & & $\begin{array}{l}\mathrm{H}-\mathrm{P} 2 \\
(\mathrm{Cr}-\mathrm{M})\end{array}$ & -1.75 & -1.75 & 1.85 & -2.94 & 3.6 & $\begin{array}{l}\text { H-P2 } \\
(\mathrm{Cr}-\mathrm{M})\end{array}$ & -3.28 & -7.83 & -4.99 & -5.79 & 2.84 \\
\hline & & & & & & $\begin{array}{l}\text { H-P1 } \\
\text { (M-Cr) }\end{array}$ & -1.75 & -3.82 & 8.05 & -2.91 & 11.87 & $\begin{array}{l}\mathrm{H}-\mathrm{P} 1 \\
(\mathrm{M}-\mathrm{Cr})\end{array}$ & -3.28 & -6.26 & -3.11 & -7.9 & 3.15 \\
\hline & & & & & & $\begin{array}{c}\text { H-P2 } \\
(\mathrm{M}-\mathrm{Cr})\end{array}$ & -1.75 & -3.93 & 4.34 & -2.83 & 8.27 & $\begin{array}{l}\text { H-P2 } \\
(\mathrm{M}-\mathrm{Cr})\end{array}$ & -3.28 & -8.26 & -5.19 & -5.16 & 3.07 \\
\hline & & & & & & $\begin{array}{l}\text { H-P1 } \\
\text { (O-O) }\end{array}$ & -1.75 & -1.75 & 4.68 & -1.57 & 6.43 & $\begin{array}{l}\text { H-P1 } \\
\text { (O-O) }\end{array}$ & -3.28 & -8.15 & -4.21 & -9.53 & 3.94 \\
\hline & & & & & & $\begin{array}{l}\text { H-P2 } \\
(\mathrm{O}-\mathrm{O})\end{array}$ & -1.75 & -1.75 & 6.57 & -1.56 & 8.32 & $\begin{array}{l}\mathrm{H}-\mathrm{P} 2 \\
(\mathrm{O}-\mathrm{O})\end{array}$ & -3.28 & -7.83 & -3.47 & -7.93 & 4.36 \\
\hline
\end{tabular}

\section{$\mathrm{Cr}_{2} \mathrm{O}_{3}$ Oxide Surfaces}

The results obtained for the different propane activation paths evaluated across the unmodified surface of chromium (III) oxide are presented in Fig 3. The figure presents the propane activation across $\mathrm{O}-\mathrm{Cr}$ pair sites for $\mathrm{H}-\mathrm{C} 1$ bond activation, which was more favourable than the $\mathrm{H}-\mathrm{C} 2$ bond due to its lower activation energy of $1.46 \mathrm{eV}$. The activation of propane across $\mathrm{Cr}-\mathrm{O}$ pair sites for $\mathrm{H}-\mathrm{C} 1$ bond activation was identified to be more energetically feasible than $\mathrm{H}-\mathrm{C} 2$ due to its lower activation energy $(5.44 \mathrm{eV})$. Likewise, $\mathrm{Cr}-\mathrm{Cr}$ pair sites identified $\mathrm{H}$ $\mathrm{C} 1$ bond activation to be more favourable due to its lower energy barrier $(3.97 \mathrm{eV})$. The pairs of the activation sites confirm $\mathrm{H}-\mathrm{C} 1$ bonds to be more feasible than $\mathrm{H}-\mathrm{C} 2$, while the activation sites were found to be in the trend of $\mathrm{Cr}-\mathrm{O}>\mathrm{O}-\mathrm{O}>\mathrm{Cr}>\mathrm{O}-\mathrm{Cr}$. 


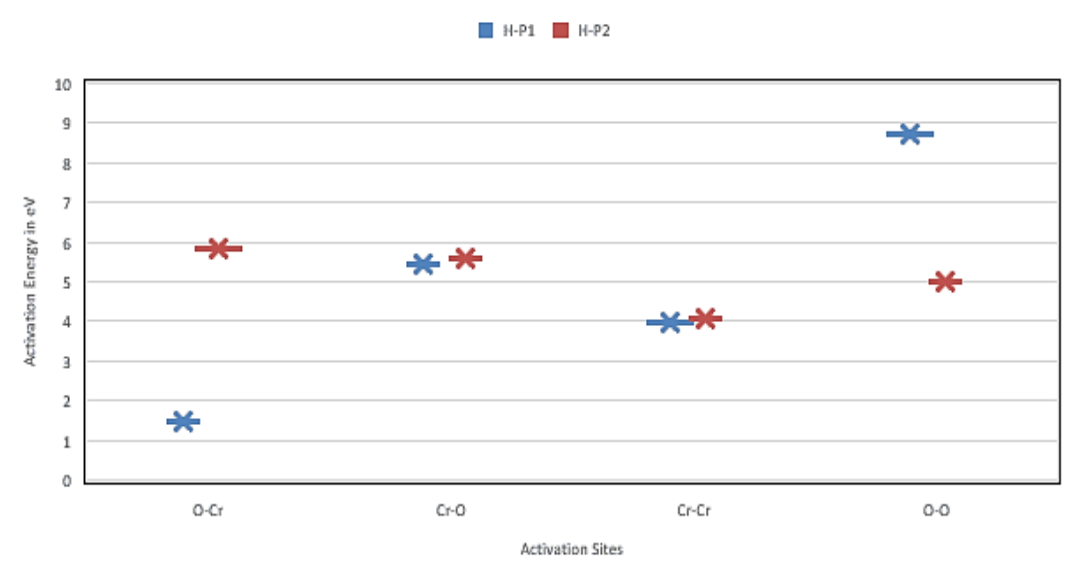

Fig. 3. Activation Energy Profile for $\mathrm{Cr}_{2} \mathrm{O}_{3}$ for Propane Activation

This finding shows that $\mathrm{O}-\mathrm{Cr}$ pair sites would be energetically feasible to activate the $\mathrm{H}-\mathrm{C} 1$ bond, indicating that hydrogen $(\mathrm{H})$ would be chemically adsorbed at the $\mathrm{O}$ site while isopropyl (P1) would be absorbed through $\mathrm{C} 1$ at the $\mathrm{Cr}$ site on the catalyst surface. These deductions agreed with the findings made by Lillehaug [24], where $\mathrm{Cr}$ and $\mathrm{O}$ sites were identified to be ease site propane activation.

\section{$\mathrm{CrMoO}_{3}$ Oxide Surfaces}

From the study of the surface-modified with molybdenum, the results obtained for the various propane activation mechanisms are presented in Table 2 and Fig 4 . These results indicated that $\mathrm{O}-\mathrm{Cr}, \mathrm{O}-\mathrm{M}, \mathrm{Cr}-\mathrm{O}, \mathrm{O}-\mathrm{O}$ and $\mathrm{M}-\mathrm{O}$ pair sites would energetically activate propane across the $\mathrm{H}-\mathrm{C} 1$ bond due to their lower activation energies $(2.53,5.87,6.77,6.43$, and $5.40 \mathrm{eV}$, respectively) compared to $\mathrm{H}-\mathrm{C} 2$ bond activation. And the results for the $\mathrm{Cr}-\mathrm{M}$ and $\mathrm{M}-\mathrm{Cr}$ sites indicate activating the propane across the $\mathrm{H}-\mathrm{C} 2$ bond would energetically be promising due to the lower activation energies obtained for the catalyst sites as 3.60 and $8.27 \mathrm{eV}$, respectively, compared to what was obtained for the $\mathrm{H}-\mathrm{C} 1$ bond activation, which was higher. Propyl-1 (P1) species were thermodynamically feasible for $\mathrm{O}-\mathrm{Cr}, \mathrm{O}-\mathrm{M}, \mathrm{Cr}-\mathrm{O}$, and $\mathrm{M}-\mathrm{O}$ sites except for $\mathrm{Cr}-\mathrm{M}$ and $\mathrm{M}-\mathrm{Cr}$ sites that promote the production of propyl-2 (P2) intermediate species.

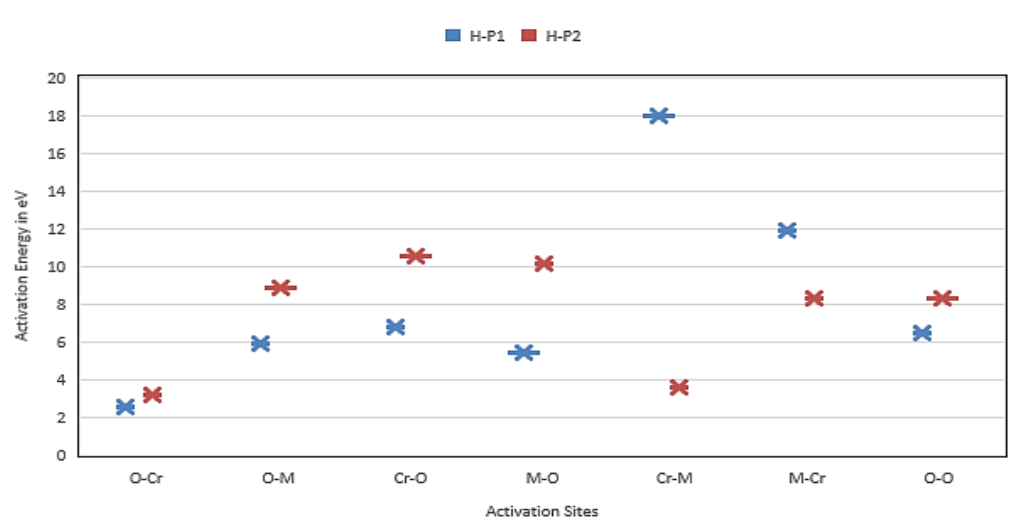

Fig. 4. Activation Energy Profile for $\mathrm{CrMoO}_{3}$ for Propane Activation

The activation energy trends for the thermodynamically feasible species were in the order: $\mathrm{M}-\mathrm{Cr}>\mathrm{Cr}-\mathrm{O}>\mathrm{O}-\mathrm{O}>\mathrm{O}-\mathrm{M}>\mathrm{M}-\mathrm{O}>\mathrm{Cr}-\mathrm{M}>\mathrm{O}-\mathrm{Cr}$. The activation energies computed for propane activation across different sites indicate that $\mathrm{O}-\mathrm{Cr}$ would thermodynamically be favourable due 
to its lower energy demand $(2.53 \mathrm{eV})$ to get activated on the surface. This deduction was found to be like findings made for the activation of propane of an unmodified surface. Though, its activation energy was found to be higher than that of the unmodified surface.

\section{$\mathrm{CrWO}_{3}$ Oxide Surfaces}

The results obtained from the study of propane activation on tungsten - modified surface are presented in Table 2, and Fig. 5 indicates that $\mathrm{H}-\mathrm{C} 1$ bond activation would be more favoured across $\mathrm{O}-\mathrm{O}(3.94 \mathrm{eV}), \mathrm{O}-\mathrm{Cr}(2.95 \mathrm{eV}), \mathrm{Cr}-\mathrm{O}(2.82 \mathrm{eV})$, and $\mathrm{M}-\mathrm{O}(1.18 \mathrm{eV})$ pair sites due to lower activation energy observed when compared to $\mathrm{H}-\mathrm{C} 2$ bond activation. $\mathrm{H}-\mathrm{C} 2$ bond activation was found to be energetically favourable for the pairs of O-M (1.95 eV), Cr-M (2.84 eV), and M-Cr $(3.07 \mathrm{eV})$ sites when compared to $\mathrm{H}-\mathrm{C} 1$ bond activation.

The trend of the activation energies for the different activation sites goes thus: $\mathrm{M}-\mathrm{Cr}>\mathrm{O}-$ $\mathrm{Cr}>\mathrm{Cr}-\mathrm{M}>\mathrm{O}-\mathrm{O}>\mathrm{Cr}-\mathrm{O}>\mathrm{O}-\mathrm{M}>\mathrm{M}-\mathrm{O}$. It can be observed in Fig. 5. However, the activation energies computed for propane activation across different sites indicate that the M-O site would be thermodynamically favourable due to its lower energy barrier of $1.18 \mathrm{eV}$, which would activate the propane across the $\mathrm{H}-\mathrm{C} 1$ bond on its surface.

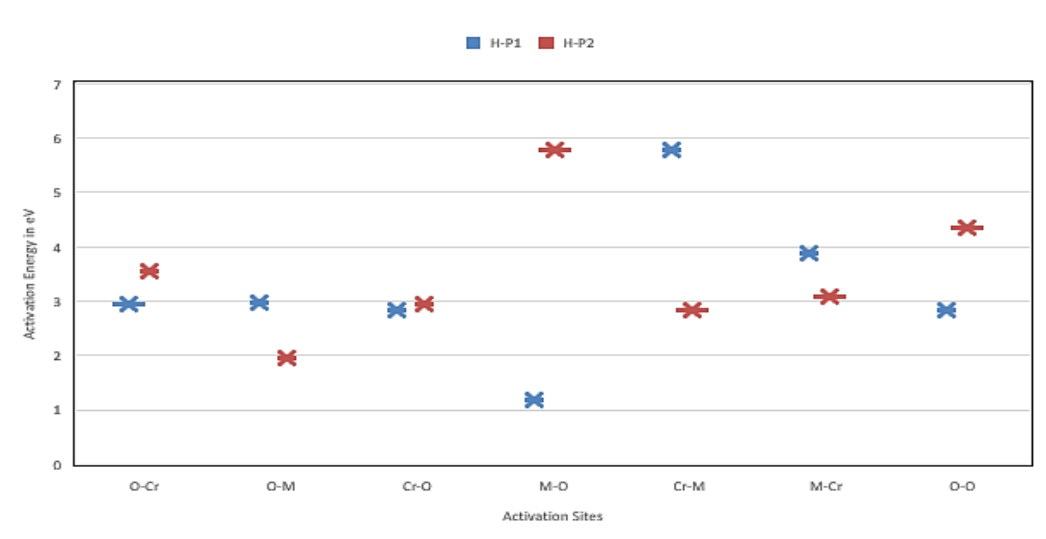

Fig. 5. Activation Energy Profile for CrWO3 for Propane Activation

The observation was found to be like the deduction made for propane activation on the unmodified surface, except its activation energy, which was lower than that of the unmodified surface. This finding was found to agree with the experimental findings reported by Yun et al. [25] and Salamanca-Guzmán et al. [26], which identifies that tungsten-based metallic oxides better enhances the dehydrogenation of propane into propylene.

\section{Evaluation of Propane Adsorption over CrM-Oxide Surfaces}

The adsorption strength of the different surfaces with the activation species, that is, hydrogen $(\mathrm{H})$ and isopropyl ( $\mathrm{P} 1$ or $\mathrm{P} 2)$, were evaluated and presented in Table 3 for unmodified $\left(\mathrm{Cr}_{2} \mathrm{O}_{3}\right)$, molybdenum-modified $\left(\mathrm{CrMoO}_{3}\right)$, and tungsten-modified $\left(\mathrm{CrMoO}_{3}\right)$ surfaces.

\section{$\mathrm{Cr}_{2} \mathrm{O}_{3}$ Oxide Surfaces}

The adsorption study of the binding strength of the activation species across the various activation sites presented in Table 3 shows that the transition-state structures generally showed the weakest strength, followed by the physically bonded propane on the surface of the catalyst. The intermediate products (also known as the activation products or species that are isopropyl and hydrogen) were found to show a stronger binding strength, which was identified to be due to the chemical bonding between the species and the surface. 
However, hydrogen $(\mathrm{H})$ and propyl-1 (P1) adsorbed across $\mathrm{O}$ and $\mathrm{Cr}$ site respectively was found to show the highest adsorption strength $(-6.60 \mathrm{eV})$, which was identified to be an energetically feasible activation route for the propane on $\mathrm{Cr}_{2} \mathrm{O}_{3}$ catalyst. Whereas hydrogen $(\mathrm{H})$ and propyl-2 (P2) adsorbed across $\mathrm{O}$ and $\mathrm{O}$ sites respectively were found to show the lowest adsorption strength $(-3.12 \mathrm{eV})$ among the activation species adsorbed.

\section{$\mathrm{CrMoO}_{3}$ Oxide Surfaces}

The study of the results presented in Table 3 similarly indicates that the TS structures generally showed the weakest strength, followed by the physically bonded propane on the catalyst's surface. The intermediate products (also known as the activation products or species, that is, isopropyl and hydrogen) were found to show a stronger binding strength, which was identified to be due to the chemical bonding between the species and the surface. It was observed that the physical adsorption of propane across the $\mathrm{Cr}$ site of the Mo-modified surface shows a weaker strength when compared to that obtained of the unmodified-surface, while that of the propane physically adsorbed across the $\mathrm{M}$ (Mo) site on the modified surface shows a stronger strength.

Table 3. Results of Adsorption Energy for Propane Adsorption over Different Surfaces

\begin{tabular}{|c|c|c|c|c|c|c|c|c|c|c|}
\hline \multirow[b]{2}{*}{ Site } & \multirow[b]{2}{*}{$\begin{array}{l}\text { Free } \\
\mathrm{C}_{3} \mathrm{H}_{8} \\
(\mathrm{eV})\end{array}$} & \multicolumn{3}{|c|}{ Initiated $\mathrm{C}_{3} \mathrm{H}_{8}(\mathrm{eV})$} & \multicolumn{3}{|c|}{$\mathrm{TS}(\mathrm{eV})$} & \multicolumn{3}{|c|}{$\mathrm{H}-\mathrm{C}_{3} \mathrm{H}_{7}$ adsorption $(\mathrm{eV})$} \\
\hline & & 今. & $\stackrel{\Omega}{3}$ & § & م & $\begin{array}{l}\Omega \\
3 \\
0 \\
0\end{array}$ & $\overbrace{0}^{-1}$ & م) & $\begin{array}{l}3 \\
3 \\
8 \\
0\end{array}$ & હ \\
\hline $\mathrm{H}-\mathrm{P} 1(\mathrm{O}-\mathrm{Cr})$ & 0 & -1.05 & -0.002 & -4.87 & -3.32 & -1.20 & -5.65 & -6.60 & -4.39 & -9.95 \\
\hline $\mathrm{H}-\mathrm{P} 2$ (O-Cr) & 0 & -0.88 & -0.002 & -4.55 & 1.6 & -0.23 & -4.36 & -6.01 & -3.89 & -7.22 \\
\hline H-P1 (O-M) & & & -2.07 & -2.98 & & 0.07 & -3.73 & & -3.37 & -9.02 \\
\hline H-P2 (O-M) & & & -2.18 & -4.98 & & 3.31 & -6.4 & & -3.46 & -7.00 \\
\hline $\mathrm{H}-\mathrm{P} 1(\mathrm{Cr}-\mathrm{O})$ & 0 & -1.05 & -0.002 & -4.87 & 0.66 & 3.04 & -5.78 & -5.17 & -6.32 & -9.67 \\
\hline $\mathrm{H}-\mathrm{P} 2(\mathrm{Cr}-\mathrm{O})$ & 0 & -0.88 & -0.002 & -4.55 & 1.32 & 7.13 & -4.97 & -4.77 & -5.72 & -9.39 \\
\hline H-P1 (M-O) & & & -2.07 & -2.98 & & -0.40 & -5.53 & & -6.65 & -8.22 \\
\hline H-P2 (M-O) & & & -2.18 & -4.98 & & 4.55 & -2.57 & & -5.89 & -7.79 \\
\hline $\mathrm{H}-\mathrm{P} 1(\mathrm{Cr}-\mathrm{Cr}) /(\mathrm{Cr}-\mathrm{M})$ & 0 & -1.05 & -0.002 & -4.87 & -0.81 & 14.27 & -4.72 & -6.49 & -4.49 & -7.43 \\
\hline $\mathrm{H}-\mathrm{P} 2(\mathrm{Cr}-\mathrm{Cr}) /(\mathrm{Cr}-\mathrm{M})$ & 0 & -0.88 & -0.002 & -4.55 & -0.16 & 0.23 & -5.08 & -6.40 & -4.56 & -5.88 \\
\hline $\mathrm{H}-\mathrm{P} 1(\mathrm{M}-\mathrm{Cr})$ & & & -2.07 & -2.98 & & 6.07 & -3.56 & & -4.89 & -8.35 \\
\hline H-P2 (M-Cr) & & & -2.18 & -4.98 & & 2.72 & -5.28 & & -4.45 & -5.25 \\
\hline H-P1 (O-O) & 0 & -1.05 & -0.002 & -4.87 & 3.95 & 2.70 & -4.66 & -3.69 & -3.55 & -9.98 \\
\hline $\mathrm{H}-\mathrm{P} 2(\mathrm{O}-\mathrm{O})$ & 0 & -0.88 & -0.002 & -4.55 & 0.76 & 4.95 & -3.56 & -3.12 & -3.18 & -8.02 \\
\hline
\end{tabular}

Evaluation of the adsorption strength across different sites indicates that adsorption of hydrogen (H) and propyl-2 (P2) across $\mathrm{M}$ (that is, Mo) and $\mathrm{O}$ site respectively shows the highest adsorption strength $(-5.89 \mathrm{eV})$ while $\mathrm{H}$ and $\mathrm{P} 2$ adsorbed across $\mathrm{O}$ and $\mathrm{M}$ (that is, Mo) site respectively was found to show the lowest adsorption strength $(-3.18 \mathrm{eV})$ among the activation species adsorbed. However, the thermodynamically feasible activation route identified as $\mathrm{O}-\mathrm{Cr}$ sites on Mo-modified catalyst was found to show adsorption energy of $-4.39 \mathrm{eV}$, which was identified to be less than that identified for the activation species across the unmodified-surface of the catalyst as $-6.60 \mathrm{eV}$.

\section{$\mathrm{CrWO}_{3}$ Oxide Surfaces}

In the study of the activation specie adsorption strength across the tungsten-modified surface of the catalyst presented in Table 3, it was observed that both chromium and tungsten sites were seen to be of a more massive binding strength for the propane physically bonded when compared to that the results obtained for the unmodified-surface. Although chromium (Cr) sits were found to be of more considerable binding strength than the propane physically adsorbed on the tungsten (W) sites, on the W-modified surface of the catalyst. It was also identified that the 
TS structures generally showed the weakest strength, followed by the physically bonded propane on the surface of the catalyst. The intermediate products (also known as the activation products or species, that is, isopropyl and hydrogen) were found to show a stronger binding strength, which was identified to be due to the chemical bond between the species and the surface.

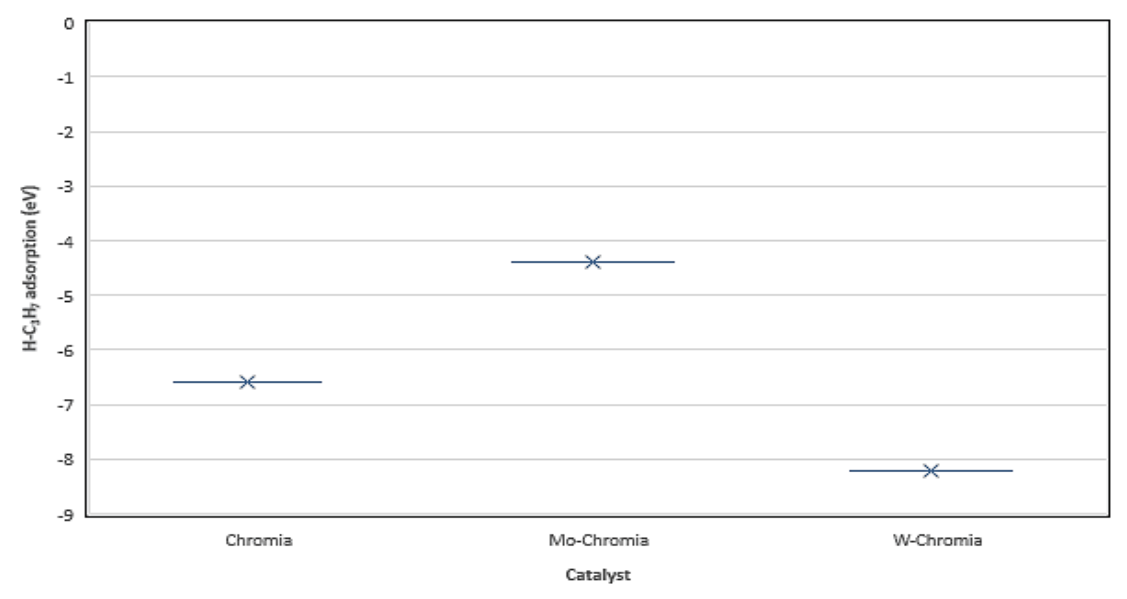

Fig. 6. Reactivity \& Acidity Parameter across CrM-oxide Surface

Moreover, the adsorption strength across sites indicates that adsorption of hydrogen $(\mathrm{H})$ and propyl-1 (P1) across $\mathrm{O}$ and $\mathrm{O}$ site respectively shows the highest adsorption strength (-9.98 $\mathrm{eV}$ ) while hydrogen $(\mathrm{H})$ and propyl-2 (P1) adsorbed across $\mathrm{M}$ (that is, $\mathrm{W}$ ) and $\mathrm{Cr}$ site respectively was found to show the lowest adsorption strength $(-5.25 \mathrm{eV})$ among the activation species adsorbed. It was further identified that the adsorption energy of activation species across the unmodified-surface strength was found to be relatively low compared to that obtained for the thermodynamically feasible route identified as $\mathrm{M}-\mathrm{O}$ sites on the W-modified surface of the catalyst with an adsorption energy of $-8.22 \mathrm{eV}$.

However, the isopropyl adsorption energy (Eads) of the Mo-surface was found to be the least, while W-surface was the highest, as shown in Fig. 6. It also identified Eads to be a good reactivity descriptor for the propane activation process.

\section{Relationship of Acidity and Reactivity on CrM-Oxide Surfaces}

The propane activation route with the least activation energy, Ea (min), was identified on each of the catalysts are presented in Table 4, where the highest Lewis acidity, aAc (max) when using either ammonia (a) or pyridine (p) probe, the adsorption energy (Eads), and the energy bandgap (Egap).

Table 4. Acidity and Reactivity Parameters Collected on the CrM-oxide Surface

\begin{tabular}{|c|c|c|c|c|c|c|}
\hline Catalyst & $\mathrm{aAc}^{(\operatorname{avg})^{\mathrm{a}}}$ & pAc (avg) $)^{\mathrm{a}}$ & Ac (overall avg) & $\mathrm{Ea}(\mathrm{min})$ & Eads & Site \\
\hline $\mathrm{Cr}_{2} \mathrm{O}_{3}$ & -5.08 & -5.59 & -5.34 & 1.46 & -6.60 & $\mathrm{O}-\mathrm{Cr}$ \\
\hline $\mathrm{CrMoO}_{3}$ & -4.39 & -4.94 & -4.67 & 2.53 & -4.39 & $\mathrm{O}-\mathrm{Cr}$ \\
\hline $\mathrm{CrWO}_{3}$ & -8.99 & -10.05 & -9.52 & 1.18 & -8.22 & $\mathrm{M}-\mathrm{O}$ \\
\hline
\end{tabular}

Note: 'a' is Oyegoke et al. [18], aAc is probe (ammonia) adsorption energy, pAc is probe (pyridine) adsorption energy, and 'avg' is average.

The correlation analysis of the ammonia (aAc) and pyridine (pAc) based Lewis acidity with the propane activation energy (Ea) and adsorption energy (Eads) of propane activation intermediates species such as isopropyl and hydrogen is presented in Table 5. 
Table 5. Correlation Coefficients for Acidity and Reactivity Relationship

\begin{tabular}{lccc}
\hline & Ac (overall avg) & Ea (min) & Eads \\
\hline Ac (overall avg) & 1.0 & & \\
Ea (min) & 0.8 & 1.0 & \\
Eads & 0.9 & 1.0 & 1.0 \\
\hline
\end{tabular}

This analysis indicates the Lewis acidity measured in terms of average probe adsorption energies were identified to show a correlation coefficient of 0.8 and 0.9 with their activation energy and adsorption energy, respectively. This relationship between the catalyst acidity and reactivity from this correlation implies that the catalyst Lewis acidity showed a good and direct relation with the activation energy and adsorption energy. Moreover, the activation energy (Ea) was found to show a good and direct relation with adsorption energy (Eads) with a correlation of 1. which corroborates with the literature [27].

The introduction of tungsten was identified to have increased the acidity and adsorption energy with decreased activation energy, while molybdenum slightly reduced acidity and adsorption energy with increased activation energy on the surface of chromium (III) oxide catalyst. These findings agree with the experimental report of Yun et al. [25], in which the introduction of tungsten-based oxide was identified to exhibit a superior catalytic activity relative to unmodified chromium (III) oxide.

\section{Conclusions}

The study of the propane activation mechanism across the surface of CrM-oxides $(\mathrm{M}=$ $\mathrm{Cr}$, Mo, and W) identifies O-Cr pair sites were found to be a thermodynamically feasible route for the activation of $\mathrm{H}-\mathrm{C} 1$ (i.e., propane activation at the alpha-carbon) with a lesser energy demand on the unmodified-surface. The modification of the surface using tungsten (W) was found to have speed up the rate of propane activation on the $\mathrm{H}-\mathrm{C} 1$ bond across $\mathrm{W}-\mathrm{O}$ pair sites. This finding was due to the lower activation energy shown for the route.

The adsorption strength of the different surfaces for the activation species), that is, hydrogen and isopropyl) along the identified thermodynamically possible activation path, was found to be $-6.60,-4.39$, and $-8.22 \mathrm{eV}$ on $\mathrm{O}-\mathrm{Cr}$, O-Cr, and $\mathrm{M}-\mathrm{O}$ sites across the unmodified, molybdenum-modified and tungsten-modified surfaces. The surface-modified with molybdenum was the most stable, though it shows higher activation energy than other surfaces.

The relationship between acidity and reactivity on CrM-oxide surfaces was established to be a direct relation due to the good and positive correlation coefficients obtained for the different acidity and reactivity parameters considered in this study. The findings confirm that the higher the acidity, the higher the reactivity, which is, the higher the Lewis acidity, the lower the activation energy, the higher the catalyst binding strength. Therefore, the introduction of tungsten would increase the acidity and adsorption energy but decrease the activation energy, while molybdenum would slightly reduce acidity and adsorption energy but increase the activation energy on the surface of chromium (III) oxide catalyst. Based on the computations' findings, this study suggests introducing tungsten metal on chromium(III)oxide catalyst to improve its propane activation rate while molybdenum could improve stability.

\section{Acknowledgment}

The authors wish to acknowledge the support of the PTDF for funding the first author's program. 


\section{References:}

[1] S. Budavari, Propylene. The Merck Index, 12th ed., New Jersey: Merck \& Co., 1996, p. 1348-1349.

[2] Y. Ren, F. Zhang, W. Hua, Y. Yue, and Z. Gao, ZnO supported on high silica HZSM-5 as new catalysts for dehydrogenation of propane to propene in the presence of $\mathrm{CO}_{2}$, Catalysis Today, 148(3-4), 2009, pp. 316-322.

[3] W. Wannapakdee, T. Yutthalekha, P. Dugkhuntod, K. Rodponthukwaji, A. Thivasasith, S. Nokbin, T. Witoon, S. Pengpanich, and C. Wattanakit, Dehydrogenation of Propane to Propylene Using Promoter-Free Hierarchical Pt/Silicalite-1 Nanosheets, Catalysts, 9(174), 2019, pp. 1-13.

[4] Y. Xie, R. Luo, G. Sun, S. Chen, Z.-J. Zhao, R. Mua, and d. J. Gong, Facilitating the reduction of $\mathrm{V}-\mathrm{O}$ bonds on $\mathrm{VOx} / \mathrm{ZrO} 2$ catalysts for non-oxidative propane dehydrogenation, Chemical Science, 11, 2020, pp. 3845-3851.

[5] T. Oyegoke, F. N. Dabai, A. Uzairu, and B. Y. Jibril, Mechanistic insight into propane dehydrogenation into propylene over chromium (III) oxide by cluster approach and Density Functional Theory calculations, European Journal of Chemistry, 11(4), 2020, pp. 342350.

[6] T. Oyegoke, F. N. Dabai, A. Uzairu, and B. Y. Jibril, Density functional theory calculation of propane cracking mechanism over chromium (III) oxide by cluster approach, Journal of the Serbian Chemical Society, 85, 2020, In-press.

[7] J. Gascón, C. Téllez, J. Herguido, and M. Menéndez, Propane dehydrogenation over a Cr2O3/Al2O3 catalyst: transient kinetic modeling of propene and coke formation, Applied Catalysis A: General, 248(1-2), 2003, pp. 105-116.

[8] Research \& Market, Global Polypropylene Market Report 2020 - Rising Demand for Thermoplastic Materials, Research \& Market Publisher, Dublin, Ireland., 2020.

[9] W. Yanbiao, G. Xinxin, and W. Jinla, Comparative DFT Study of Structure and Magnetism of TMnOm (TM = Sc - Mn, $n=1-2, m=1-6)$ Clusters, Physical Chemistry Chemical Physics, 12(1), 2010, pp. 2471-2477.

[10] L. Ming, A. Yi, G. Xing, J. Zhi, and C. De, First-Principles Calculations of Propane Dehydrogenation over PtSn Catalysts, ACS Catalysis, 2(6), 2012, p. 1247-1258.

[11] N. Lauri and H. Karoliina, Selectivity in Propene Dehydrogenation on Pt and Pt3Sn Surfaces from First Principles, ACS Catalysis, 3(1), 2013, p. 3026-3030.

[12] H. Timothy, Computational study of the catalytic dehydrogenation of propane on Pt and Pt3Ga catalysts, Thesis, Ghent University, 2015.

[13] S. Stephanie, K. Maarten, V. Vladimir, A. Evgeniy, R. Marie-Françoise and B. Guy, The Positive Role of Hydrogen on the Dehydrogenation of Propane on Pt (111), ACS Catalysis, 7(11), 2017, p. 7495-7508.

[14] P. Biloen, F. Dautzenberg and W. Sachtler, Catalytic dehydrogenation of propane to propene over platinum and platinum-gold alloys, Journal of Catalysis, 50(1), 1977, pp. $77-86$. 
[15] H. Li, Y. Yue, C. Miao, Z. Xie, W. Hua, and Z. Gao, Dehydrogenation of ethylbenzene and propane over $\mathrm{Ga} 2 \mathrm{O} 3-\mathrm{ZrO} 2$ catalysts in the presence of $\mathrm{CO} 2$, Catalysis Communications, 8(9), 2007, pp. 1317-1322.

[16] Y. Ming-Lei, Z. Yi-An, F. Chen, S. Zhi-Jun, C. De and Z. Xing-Gui, DFT study of propane dehydrogenation on Pt catalyst: effects of step sites, Physical Chemistry, Chemical Physics, 13(1), 2011, p. 3257-3267.

[17] T. Oyegoke, F. Dabai, A. Uzairu and B. Jibril, Insight from the Study of Acidity and Reactivity of Cr2O3 Catalyst in Propane Dehydrogenation: A Computational Approach, Bayero Journal of Pure and Applied Sciences, 11(1), 2018, pp. 178-184.

[18] T. Oyegoke, F. N. Dabai, U. Adamu and Y. J. Baba, Quantum mechanical calculation of molybdenum and tungsten influence on the CrM-oxide catalyst acidity, Hittite Journal of Science \& Engineering, 7(4), 2020, pp. 1-29.

[19] C. Compere, D. Costa, L.-H. Jolly, E. Maugerc and C. Giessner-Prettre, Modeling of the adsorption on Cr2O3 clusters of small molecules and ions present in seawater. A preliminary non-empirical study, New J. of Chem, 24(12), 2000, pp. 993-998.

[20] J. Warren, A Guide to Molecular Mechanics and Quantum Chemical Calculations, Irvine, CA: Wavefunction, 2003.

[21] H. Warren and O. Sean, Spartan 16 for Windows, Macintosh and Linux: User Guide and Tutorial, CA: Wavefunction, 2017, pp. 435-518.

[22] C. Liu, G. Li, Emiel, J. Hensen and E. Pidko, Relationship between acidity and catalytic reactivity of faujasite zeolite: A periodic DFT study, Journal of Catalysis, 344(1), 2016, p. $570-577$.

[23] C. Liu, I. Tranca, R. A. van Santen, E. J. Hensen and E. A. Pidko, Scaling relations for acidity and reactivity of zeolites, The Journal of Physical Chemistry C, 121(42), 2017, pp. 23520-23530.

[24] S. Lillehaug, A Theoretical Study of Cr/oxide Catalysts for Dehydrogenation of Short Alkanes, University of Bergen Publisher, 2006.

[25] Y. Yun, J. R. Araujo, G. Melaet, J. Baek, B. S. Archanjo, M. Oh and G. A. Somorjai, Activation of Tungsten Oxide for Propane Dehydrogenation and Its High Catalytic Activity and Selectivity, Catalysis Letter, 147(3), 2017, pp. 622-632.

[26] M. Salamanca-Guzmán, Y. E. Licea-Fonseca, A. Echavarría-Isaza, A. Faro and L. A. Palacio-Santos, Oxidative dehydrogenation of propane with cobalt, tungsten and molybdenum based material, Revista Facultad de Ingeniería Universidad de Antioquia, 84(1), 2017, pp. 97-104.

[27] L. Zhang, Y.-Q. Su, M.-W. Chang, I. A. W. Filot and E. J. M. Hensen, Linear Activation Energy-Reaction Energy Relations for LaBO3 $(B=\mathrm{Mn}, \mathrm{Fe}$, Co, Ni) Supported Single-Atom Platinum Group Metal Catalysts for CO Oxidation, The Journal of Physical Chemistry C, 123(51), 2019, p. 31130-31141.

[28] S. Veliah, K. Xiang, R. Pandey, J. Recio, and J. Newsam, Density Functional Study of Chromium Oxide Clusters: Structures, Bonding, Vibrations, and Stability, J. Phys. Chem. B, 102(1), 1997, pp. 1126-1135. 
[29] P. A. Garrain, D. Costa and P. Marcus, Biomaterial-biomolecule interaction: DFT-D study of glycine adsorption on Cr2O3, The Journal of Physical Chemistry C, 115(3), 2010, pp. 719-727.

[30] E. V. Shah and D. R. Roy, Magnetic switching in Crx $(x=2-8)$ and its oxide cluster series, Journal of Magnetism and Magnetic Materials, 451, 2018, pp. 32-37.

[31] N. Dzade, A. Roldan and N. de Leeuw, A density functional theory study of the adsorption of benzene on hematite ( $\alpha$-Fe2O3) surfaces, Minerals, 4(1), 2014, pp. 89-115.

[32] K. C. Lau, A. K. Kandalam, A. Costales and R. Pandey, Equilibrium geometry and electron detachment energies of anionic Cr204, Cr2O5, and Cr2O6 clusters, Chemical Physics Letters, 393(1-3), 2004, pp. 112-117.

[33] F. Maldonado and A. Stashans, DFT modeling of benzoyl peroxide adsorption on $\alpha-C r 2 O 3$ (0001) surface, Surface Review and Letters, 23(5), 2016, p. 1650037.

[34] A. Bendjeddou, T. Abbaz, A. K. Gouasmia, and D. Villemin, Molecular structure, HOMOLUMO, MEP and Fukui function analysis of some TTF donor substituted molecules using DFT (B3LYP) calculations, Int Res J Pure Appl Chem, 12(1), 2016, pp. 1-9.

[35] D. Guo-Liang, L. Zhen-Hua, L. Jing, W. Wen-Ning and F. Kang-Nian, Deep Oxidation in the Oxidative Dehydrogenation Reaction of Propane over V2O5(001): Periodic DFT Study, The Journal of Physical Chemistry C, 116(1), 2012, pp. 807-817.

[36] D. Satyajit, K. Nand, J. Plaban and C. Ramesh, DFT Insight on Oxygen Adsorbed Pt Trimer Cluster (Pt3) for CO Oxidation, Computational and Theoretical Chemistry, 1114(1), 2017, pp. 1-7.

[37] Z. H. Ma, J. Wang, S. Li, A. J. Jiang, J. Li, C. H. An and L. Y. Sun, Effect of air addition on the catalytic performance of Pt-Sn/Al2O3 catalysts in propane dehydrogenation, IOP Conf. Series: Materials Science and Engineering, 479(012069), 2019, pp. 1-7.

[38] S. C. Purdy, R. R. Seemakurthi, G. M. Mitchell, M. Davidson, B. A. Lauderback, S. Deshpande, Z. Wu, E. C. Wegener, J. Greeley and J. T. Miller, Structural trends in the dehydrogenation selectivity of palladium alloys, Chemical Science, 11, 2020, pp. 50665081 .

Received: November 04, 2020

Accepted: December 08, 2020 